\title{
CODIFICAÇÃO E DESCODIFICAÇÃO: UMA ANÁLISE ACERCA DO TEMA
}

\author{
Antonio Carlos Morato \\ Mestre e Doutorando em Direito Civil pela Faculdade \\ de Direito da Universidade de São Paulo
}

Resumo:

A extensão da codificação e as polêmicas tesćs que a envolvem, e os questionamentos em torno das novas teses, tais como a centralização das ṇormas do juiz, também tratada como sistema aberto.

\begin{abstract}
:
The extension of the codification and the polemical tesis that involves it, and the questions involving the new tesis, such as the centralization of the judges norms, also treated as an open system.
\end{abstract}

Unitermos: Codificação; Descodificação; Novo Código Civil.

\section{Introdução.}

Com a vigência do novo Código Civil (Lei n. 10.406/02), observou-se que o debate envolvendo a conveniência da codificação no mundo contemporâneo foi relegado a um segundo plano, tendo em vista que o Código Civil tornou-se um fato consumado, com seus defeitos e qualidades.

Entretanto, consideramos que o antagonismo entre os que defendem a codificação e os que consideram preferível a aprovação de leis especiais, sustentando que estamos em uma fase de descodificação ainda não terminou, até porque tal discussão ainda apresenta considerável utilidade na fixação das premissas necessárias à elaboração de normas que possam obter efetivamente a pacificação social.

Henri Capitant, professor da Faculdade de Direito da Universidade de Paris, após constatar que a codificação estabeleceu-se em diversos paises, destacou que sua principal utilidade seria a unificação do Direito.'

1. Segundo Henri Capitant, "la codification est un phènomène qui se produit chez la plupart des peuples, à un moment donné de leur existence. Elle sert principalement à unifier le droit" (Cf. Henri Capitant . Introduction a l'étude du Droit Civil : Notions Générales . 3a ed. . p. 64). 
Assim, a codificação, na definição de Miguel Maria de Serpa Lopes corresponderia a todas as normas, de certo ramo do Direito, que vigoram em determinado momento histórico e que, principalmente, "passam a viver sob um regime de unidade orgânica, modificando ou inovando profundamente todo o Direito de um Estado"”

A unidade orgânica é a mais importante característica de um código, como também ressalta Tércio Sampaio Ferraz Júnior, para quem "o que caracteriza o código é a regulação unitária de um ramo do Direito (Código Civil, Comercial, Penal, etc.), estabelecendo-se para ele uma disciplina fundamental"3

Na seqüência de tais esclarecimentos, ressaltamos que desenvolvemos o presente estudo tentando responder à seguinte questão: $\dot{E}$ possivel prever todas as condutas humanas, em especial no Código Civil (enquanto lei geral), em um mundo no qual ocorre um processo de mutação cada vez mais acelerado?

Poderíamos até considerar que tal indagação já foi respondida no passado, dado que Jean Portalis, considerado o mais importante entre os autores do Código Civil francês de 1804, concluiu que a pretensão de prever os vários aspectos da vida humana era algo absolutamente impraticável (e isso numa sociedade muito menos complexa do que a que vivemos contemporaneamente).

Nesse sentido, no Discurso Preliminar ao Código Civil francês, Jean Portalis ponderava, ainda na transição entre os séculos XVIII e XIX, que "evitamos a perigosa ambição de querer regular e prever tudo, mas os mesmos para quem um código parece algo volumoso demais pretendem exigir do legislador a terrivel tarefa de nada abandonar à decisão do magistrado. Por mais que se tente, as leis não poderiam substituir completamente o uso da razão natural nos negócios da vida, pois as necessidades da sociedade são tão variadas, a comunicação entre os homens é tão ativa, seus interesses tão distintos e suas relações tão extensas que seria impossivel para o legislador prever tudo" 4

2. Cf. Miguci Maria de Scrpa Lopes . Curso de Direilo Civil v. 1 . 8a cd. . p. 125

3. Cf. Tércio Sampaio Ferraz Júnior. Introdução ao Estudo do Direito: técnica, decisão, dominação. 2a cd. p. 237

4. Cf. Jcan Eticnne Maric Portalis. Discurso Preliminar al Código Civil Francés tradução de I. Cremades c L. Gutićrrez-Masson. pp. 35-36 (A transcrição parcial, no corpo do texto ć uma tradução livrc, mas frisamos que, na tradução do texto original para o espanhol, consta que "nos hemos preservacto igualmente de la peligrosa ambición de querer regular y preverlo todo. Quién prodria pensar que son aquellos mismos a los que un código les parece siempre demasiado voluminoso, quienes se atreven a prescribir imperiosamente al legislador la terrible tarea de no abandonar nada a la decisión del juez? Hágase lo que se haga, las leyes positivas no sabrian nunca substituir completamente el uso dela razón natural en los negócios de la vida. Las necesidades de la sociedad son tan variadas, la comunicación de 
A visão de Portalis, era não-só racional como necessária, pois apontava a preocupação com as dificuldades que uma lei atravessaria para continuar a ser eficaz na sociedade.

Realmente, em nosso País, tais preocupações também não afastaram a convicção acerca da utilidade de um código, particularmente quando é necessário optar entre a redação de um novo código e a simples reforma do anterior.

Nesse contexto, merece destaque a exposição de motivos apresentada pelo então Ministro da Justiça Alfredo Buzaid, para quem a elaboração do Código de Processo Civil de 1973 teria sido mais útil do que a reforma paulatina do Código de Processo Civil de 1939: "mas a pouco e pouco nos convencemos de que era mais dificil corrigir o Código velho que escrever um novo. A emenda ao Código atual requeria um concerto de opiniões, precisamente nos pontos em que a fidelidade aos principios não tolera transigências (...) O grande mal das reformas parciais é o de transformar o Código em mosaico, com coloridos diversos que traduzem as mais variadas direções". 5.

Também merece destaque a exposição de motivos do prof. Miguel Reale, que presidiu a comissão responsável pela redação da Lei n. 10.406/02 (o novo Código Civil brasileiro), que criticava os que preferiam a descodificação, ao dizer que "nem se diga que nossa época é pouco propicia à obra codificadora, tantas e tamanhas são as forças que atuam neste mundo em contínua transformação, pois, a prevalecer tal entendimento, só restaria ao jurista o papel melancólico de acompanhar passivamente o processo histórico, limitando-se a interferir, intermitentemente, com leis esparsas e extravagantes" ${ }^{6}$

De fato, a preocupação com a finalidade da lei deve estar prevista na exposição de motivos, pois, como aponta o pensador finlandês Otto Brusiin "pode-se considerar como caso perfeitamente normal que os motivos de um determinado parágrafo da lei expressem sua finalidade prática" e, por isso mesmo, "nos trabalhos

los hombres es tan activa, sus intereses tan múltiples y sus relaciones tan extensas que le resulta imposible al legislador proveer a todo. En las materias mismas que fijan particularmente su atención hay un sinfin de detalles que se le escapan, o que son demasiado discutibles y en exceso variables como para poder llegar a ser el objeto de un texto de ley. Por lo demás, como encadenar la acción del tiempo?, cómo oponerse al curso de los acontecimentos?, o a la pendiente insensible de las contumbres? Cómo conocer y clacular por adelantado lo que sólo la experiencia puede revelarnos? Puede la previsión extenderse alguna vez a objetos que el pensamiento no puede alcanzar?").

5. Na cxposição de motivos da Lci n. 5.869, de 11 de janciro de 1973, scndo que a cxposição de motivos redigida pclo ministro Alfredo Buzaid c dirigida ao então presidente da República Emilio Garrastazu Mćdici datava de 31 de julho de 1972.

6. Cf. Migucl Rcalc O Projeto do Novo Código Civil : situação após a aprovação pelo Senado Federal .2a cd. . p. 47 
preparatórios de uma grande codificação se discutem a fundo problemas de adequação ao fim almejado", embora alerte para o fato de que "em um estado cultural da atualidade, não é fácil evitar que, nos motivos da lei, também se tratem, em ocasiões, problemas teóricos," como aparentemente pudemos notar no parágrafo anterior, no qual Miguel Reale trata da finalidade da lei, sem esquecer do embate teórico.

Todavia, também acreditamos que as dúvidas e perplexidades até aqui relatadas aprofundam-se cada vez mais, não apenas na Doutrina, mas fundamentalmente na próprio Poder Legislativo, com a acentuada proliferação de leis que demonstrariam que a codificação teria chegado a seu próprio ocaso, sendo colocada em dúvida sua real utilidade, apesar da sempre respeitável e lúcida intervenção de Miguel Reale.

Nessa ordem de idéias, sustentava Orlando Gomes que "a maré montante das leis especiais atesta, com efeito, a impossibilidade da codificação, eis que não podem ser reduzidas a um sistema construido com outro método, outra lógica e outra filosofia. Parecerá a um jurista de breves análises que sua proliferação se deve simplesmente ao atraso histórico do Código Civil, bastando, para atualizá-lo, acertar o passo com a dinâmica da realidade dos novos tempos" e, criticando tal entendimento, frisava o fato de que apenas por comodidade diferenciava-se o Código das leis especiais, pois aquele já não era "a disciplina geral das relações jurídicas próprias da sociedade civil."

O raciocínio do eminente civilista foi complementado por Tércio Sampaio Ferraz Júnior que afirmou que "os códigos que conhecemos hoje são marcados por um espirito de rigidez e conservadorismo que contrasta, mas fornece uma impressão de segurança e certeza"

Logo, pretender a permanência e, sobretudo a estabilidade da lei em circunstâncias cada vez mais caracterizadas por uma mutabilidade acelerada das relações sociais permanece como uma conduta arriscada por parte do legislador, posto que é exigida do Poder Legislativo cada vez maior celeridade diante dos diversos problemas atuais.

2. Codificação e Consolidação.

Para entender efetivamente o movimento codificador, é conveniente distinguir a codificação, já conceituada e analisada anteriormente, da mera consolidação de leis.

7. Cf. Otto Brusiin. O Pensamento Juridico . tradução de Hebc A. M. Calctti Marenco . pp. 86-87

8. Cf. Orlando Gomes. Introdução ao Direito Civil . 14a ed. . p. 69

9. Cf. Tércio Sampaio Ferraz Júnior . Introdução ao Estudo do Direito : técnica, decisão, dominação .2a cd. . p. 238 
Ensinava Orlando Gomes que a condensação das normas jurídicas em um sistema não era uma questão recente, realizando-se por meio de dois processos: a) a consolidação e b) a codificação. ${ }^{10}$

A consolidação, para o ilustre autor consistia na "justaposição de normas vigentes", que eram articuladas sob certa orientação, ao passo que na codificação " $n a \tilde{o}$ se aproveitam apenas as leis existentes, mas se fazem eliminações, adaptações $e$ inovações" elaborando-se uma "obra metódica, sistemática" e que prima pela inovação."

Na lição histórica de Augusto Teixeira de Freitas, na Consolidação das Leis Civis, "consiste a consolidação em mostrar o último estado da legislação", pois "a consolidação será feita por títulos e artigos, em os quaes serão reduzidas a proposições claras e succintas as disposições em vigor" 12

A codificação e a consolidação podem diferenciar-se tanto no conteúdo quanto na estrutura, na lição sempre precisa de Orlando Gomes, que também afirmava que a consolidação seria uma obra "de adaptação morfológica" enquanto a codificação seria "uma obra de criação", apesar de seus objetivos serem os mesmos ${ }^{13}$

Em nosso ordenamento jurídico, cita Tércio Sampaio Ferraz Júnior o exemplo da Consolidação das Leis do Trabalho (CLT), instituída por Decreto-Lei, lembrando que a consolidação "é uma espécie de compilação de leis preexistentes, mas retirando-lhes as normas do seu contexto, reformulando-as num todo", vez que "em principio, à diferença de um código, uma consolidação não é uma inovação legal, mas uma espécie de confirmação unitária de matéria legal preexistente" e, por isso, pode a consolidação "ser estabelecida por mero decreto, como éo caso da Consolidação das Leis da Previdência Social - CLPS (Decreto n. 11.011, de 24-01-76)" 14

Sob o prisma histórico da questão, de acordo com Ricardo Lorenzetti, “a consolidação gerava insegurança, porque não se sabia se tal ou qual disposição

10. Cf. Orlando Gomes . Introdução ao Direito Civil . 14a cd. . p. 61

11. Cf. Orlando Gomes . op. cit. . p. 61

12. Complementava ainda o grande jurista do periodo imperial que, no que diz respeito às normas costumciras, "em notas correspondentes deverá citar a lei que autorisa a disposição, e declarar o costume que estiver estabelecido contra ou além do texto" (Cf. Augusto Teixcira de Frcitas . Consolidação das Leis Civis . 2a cd. . p. II)

13. Cf. Orlando Gomes. Introdução ao Direito Civil 14a cd. . p. 61

14. Cf. Tércio Sampaio Fcrraz Júnior . Introdução ao Estudo do Direito : técnica, decisão, dominação .2a cd. . p. 238 
estaria em vigor. O código é segurança, que se traduz em uma seqüência ordenada de artigos", isso porque "a imutabilidade é uma das suas características essenciais; não se pode alterar uma parte sem mudar o todo" is

O conhecido jurista argentino relata que, antes das codificações, a sociedade era regulada por meio de consolidações, posto que "estas pretendiam reproduzir o Direito sem modificá-lo, visavam apenas continuá-lo, melhorá-lo, em um continuum histórico" e, a codificação, nessa linha de análise, constituiria uma ruptura com o Direito anterior e não a sua continuidade ${ }^{16}$

Por essa mesma razão, José Reinaldo Lima Lopes distingue o movimento de codificação do Direito, da mera compilação ocorrida anteriormente em Portugal, na França, na Alemanha e na Espanha. ${ }^{17}$

Para tanto, esclarece o autor que a codificação "reflete um desejo de ordem, de hierarquia e de concentração legislativa no poder central, no Estado" e, sob esse aspecto, tais códigos foram contra a tradição e os costumes estabelecidos, pois "na verdade precisavam superar e excluir a tradição do ius commune, medieval, corporativa e confusa para os padrões do racionalismo moderno" sendo essa a razão pela qual os códigos foram elaborados por pessoas de estrita confiança do soberano "que em geral já não têm a formação filosófica dos clássicos", pois "ou são burocratas, ou são juristas não treinados não treinados na tradição universitária medieval". ${ }^{18}$

Efetivamente, não é possivel desconsiderar o argumento de que um poder central visava submeter as diversas regiões que utilizavam ainda um Direito calcado no costume e isso chegou a ocorrer até o século XIX.

Assim, basta relembrar o que ocorreu na Argentina, como demonstra o professsor titular de História do Direito da Faculdade de Direito da Pontificia Universidad Católica Argentina, Liniers de Estrada, para quem a codificação trouxe uma polêmica entre os argentinos que enxergavam na codificação um avanço do poder central sobre as províncias e os que acreditavam ser a codificação um meio para unificar o país. ${ }^{19}$

15. Cf. Ricardo Lorenzetti . Fundamentos do Direito Privado . p. 42

16. Cf. Ricardo Lorenzctti . op. cit. . p. 42

17. Cf. Josć Rcinaldo Lima Lopes . O Direito na História : lições introdutórias . p. 208

18. Cf. José Rcinaldo Lima Lopes . op. cit. . p. 208

19. Linicrs de Estrada relata o fato de que "la codificación planteó una polémica entre los que consideraban que ella significaba un avance del poder central sobre las provincias y los que la apoyaban pensando que seria un medio para contribuir a la unificación del pais. Por outra parte la constitución sancionada en 1853 y reformada en 1860 establecia bien claramente que el congresso nacional deberia 
No entanto, ainda hoje, a codificação não é uma página virada da História, pois insiste Tércio Sampaio Ferraz Júnior que "importantes são ainda hoje as simples compilações, repertórios de normas que, em geral, obedecem a critérios cronológicos, com divisões, às vezes, por matéria, e que conhecemos sobretudo quanto às decisões jurisprudenciais" e "a imposição de uma racionalidade lógica às compilações vem ganhando enorme significado atualmente, graças ao desenvolvimento da informática juridica", pois "a possibilidade de se construirem bancos de dados, de normas legais, administrativas, jurisprudenciais, de opiniões doutrinárias, está, sem dúvida, revolucionando a técnica juridica, prometendo, para um futuro próximo, uma repercussão fantástica no próprio pensamento dogmático" ${ }^{20}$

Em conclusão, por paradoxal que pareça, tanto a codificação como a consolidação (mesmo que diferentes quanto à estrutura e sistematização), discutíveis enquanto soluções permanentes para o Direito, persistem pela irresistivel atração que, tanto o legislador quanto os operadores do Direito, sentem pela unidade e aparente segurança conferida por ambas.

\section{A Codificação como Sistema.}

Destacamos anteriormente que a visão sistemática do Código era fundamental para diferenciá-lo das consolidações anteriores e, nesse sentido, advertia André Franco Montoro que "o código não é um conjunto de leis, mas uma lei única, que dispõe de modo sistemático sobre um ramo ou setor do Direito". ${ }^{11}$

É muito ilustrativa a explicação dada por José Reinaldo Lima Lopes ao apontar a ausência de sistema das ordenações em comparação com os códigos, dizendo que "quem abre as Ordenações Filipinas, que também vigoraram no Brasil desde 1603, nota que elas são casuísticas", pois ao tratar da matéria penal "não existe uma parte geral sobre as penas, os delitos, as circunstâncias atenuantes ou agravantes, o dolo ou a culpa", concluindo que tal ordenação consistia apenas numa simples coleção de delitos. ${ }^{22}$

dictar los códigos civil, comercial, penal y de mineria. Como consecuencia de ello se emprendio la tarea que culminó com el cumplimiento de aquella disposición. La codificación fuc asi una herramienta más en larga y dificil tarea de la unidad nacional, ya que una legislación uniforme en todo el pais contribuyó a afianzar aquella". (Cf. Linicrs de Estrada . Manual de Historia del Derecho . p. 167)

20. Cf. Tércio Sampaio Fcrraz Júnior. Introdução ao Estudo do Direito : técnica, decisão, dominação 2a cd. . pp. 238-239

21. Cf. André Franco Montoro. Introdução à Ciência do Direito . v. II . 7a cd. . p. 81

22. Cf. Josć Rcinaldo Lima Lopes . op. cit. . pp. 223-224 
Mesmo após tais esclarecimentos preliminares, persiste a dúvida: Como podemos compreender um sistema?

Partindo de uma abordagem verdadeiramente didática, Luiz Edson Fachin compara uma fotografia e uma moldura, sendo que o sistema enquanto moldura enquadraria as pessoas, suas relações e os bens (que corresponderiam à fotografia inserida na moldura), só que nem tudo que está contido nessa moldura corresponde ao que nela poderia estar. ${ }^{23}$

O professor da Universidade Federal do Paraná conclui dizendo que " $h a ́$ coisas que estão fora da moldura, e há também relações que estão excluidas desse quadro", mas "a realidade fática, porém, constrói sociedade à margem dessa dimensão que o sistema fixa para dar dignidade juridica". partindo da simples idéia de que os "fatos se tornam juridicos a partir de uma luz de juridicidade que recai sobre eles, o que leva à formulação de que nem todo fato é juridico e nem toda pessoa é, a rigor, sujeito de direito" 24

Em nosso país, o esboço de Código Civil, elaborado por Augusto Teixeira de Freitas, merece destaque tanto por sua importância histórica como pela sua reconhecida sistematização do Direito Civil, o que sem dúvida exige do conhecido jurista do Império, o reconhecimento de uma notável contribuição para a ciência do Direito em nivel mundial.

Em 1865, ainda na introdução da Consolidação das Leis Civis, que antecedou o Esboço, Teixeira de Freitas demonstrava sua preocupação com a codificação, ao afirmar que "nunca tivemos Código Civil e, se por tal reputássemos o corpo das Ordenações Filipinas ou antes o $4^{\circ}$ livro dellas que mais se dedicou aos contractos e sucessões, estariamos ainda assim envolvidos na immensa teia das leis extravagantes que se tem accumulado no decurso de mais de dous seculos e meio. Também não existe um só escriptor, antigo ou moderno que puramente se limitasse a colligir e ordenar o Direito pátrio", ${ }^{25}$

Pontes de Miranda resgatou, embora com críticas, a importância do esboço de Teixeira de Freitas e sua inovadora concepção sistemática, ao dizer que neste "o plano adotado foi o da dicotomia - Parte Geral (pessoas, coisas, fatos) e Parte Especial", sendo que esta "se tripartia em direitos pessoais (em geral, relações

23. Cf. Luiz Edson Fachin . Teoria Crítica do Direito Civil .p. 175

24. Cf. Luiz Edson Fachin .op. cit.. p. 177

25. Cf. Augusto Teixcira de Freitas . Consolidação das Leis Civis . 2a ed. . p. II-III 
de familia, relações civis, direitos reais (em geral, sobre coisas próprias, sobre coisas alheias) e disposições comuns a direitos pessoais e reais (herança, concurso de credores, prescrição)", considerando que "o mais admirável é a solidez, o concatenamento e a inteireza da construção juridica, com que pode erguer, com tal programa falho, com tal classificação censurável, a sua obra minudente, sagaz, em que por vezes se adivinha o que só no B.G.B. aparecerá"26

E prosseguia Pontes de Miranda, afirmando ser apenas o BGB “ainda hoje, pelo rigor técnico, superior ao esboço brasileiro de 1860. O Código Civil argentino (1869) adotou a disposição de matérias imaginada por ele; $e$, no mundo contemporâneo, só o Code Civil e o B.G.B. foram, até hoje, de tão grande influência em países estranhos. De 1869 para cá a sua atuação na América Latina é profunda, e os dispositivos de Códigos europeus e americanos que atenderam a inovações do argentino são, realmente, frutos do esboço". ${ }^{27}$

O jurista português Carlos Alberto da Mota Pinto lecionava no sentido de que "da relação entre uma parte geral e partes especiais - e de um esquema idêntico dentro das várias partes especiais - resulta que as normas contidas no código não se dispõem segundo um mero alinhamento ou contiguidade, mas segundo uma ordenação que deve estar presente no espirito do julgador ao pesquisar a disciplina legal completa de qualquer situação da vida submetida ao seu julgamento".28

A Codificação, observada quanto à sua funcionalidade, consistiria na reunião em texto único, de forma metódica e homogênea, de uma série de normas relativas a certo ramo do Direito. ${ }^{29}$

Nesse contexto, a visão de sistema deve necessariamente estar presente em um código, já que, na lição de Tércio Sampaio Ferraz Júnior, os códigos "representam um esforço técnico de dominio prático de um material, conforme as exigências de decidibilidade de conflitos em uma sociedade complexa, submetida à celeridade das transformações", dado que "por seu intermédio, o conhecimento juridico viu aplicadas

26. Cf. Pontes de Miranda . Fontes e Evolução do Direito Civil Brasileiro . $2^{\mathrm{a}} \mathrm{cd}$. pp. $97-98$

27. Cf. Pontes de Miranda . op. cit. . p. 98

28. Cf. Carlos Albcrto da Mota Pinto . Teoria Geral do Direito Civil . 3a cd. . p. 57

29. Henri Capitant dizia quc "la codification peut également devenir nécessaire, même dans les pays où le droit est déjà unifié, lorsque les lois relatives aux institutions d'une même famille juridique forment une masse compacte au millieu de laquelle la pratique a peine à se reconnaitre. Codifier, c'ést alors réunir en un seul corps, a fin d'en faciliter l'étude et d'en faire un tout homogène et méthodique, ces differentes lois". (Cf. Henri Capitant . Introduction a l'étude du Droit Civil : Notions Générales . 3a cd. . p. 65). 
técnicas de controle sistemático no sentido de se constituirem grandes redes conceituais capazes de funcionar como uma espécie de mapeamento da realidade jurídica" ${ }^{30}$

A noção de sistematização, presente nos códigos, é até mais relevante do que a unificação legislativa pretendida; pois, na lição de Miguel Maria de Serpa Lopes, "nem só a unificação constitui o objetivo da codificação, como ainda o de salutarmente contribuir para maior facilidade e perfeição do estudo do Direito, por se encontrar estratificado em sistematização cientificamente ordenada" ${ }^{31}$

Para Luiz Edson Fachin, "o sistema conforta porque dá respostas por meio de regras e presunções, e quando estas não são suficientes, cria ficções, tornandose um sistema tão pronto e acabado que não permite a ninguém que o desconhę̧a, ao menos em termos jurídicos, ainda que o ignore no plano real e material' ${ }^{32}$

Quanto à sistematização no novo Código Civil brasileiro (Lei n. 10.406/ 02), Miguel Reale salientou que "como responsável pela codificação, não vacilei no sentido de preferir uma sistematização ampla, embora partindo do código em vigor", sendo fixado "o critério de preservar, sempre que possivel, as disposições do código atual, porquanto de certa forma cada texto legal representa um patrimônio de pesquisa, de estudos, de pronunciamentos de um universo de juristas" tendo sido abandonada pela comissão "a idéia de dividir o Código Civil, elaborando-se, em separado, um Código das Obrigações", pelo fato de que "a quase-unanimidade de nossos juristas repudiou a proposta de um Código Civil decepado e sem sentido de unidade, condenando a eliminação da parte geral, tradicional em nosso Direito" ${ }^{33}$

\section{Aspectos Históricos e Políticos das Codificação.}

A preocupação em obter um corpo único de normas, com uma estrutura organizacional interna e de fácil acesso ao intérprete do texto legal não constitui uma preocupação que teria surgido apenas a partir do Código Napoleônico de 1804, como quer fazer crer principalmente certa parte da Doutrina francesa.

30. Cf. Tércio Sampaio Ferraz Júnior . Introdução ao Estudo do Direito : técnica, decisão, dominação. 2a cd. . p. 238

31. Cf. Miguel Maria de Scrpa Lopes . Curso de Direito Civil . v. 1 . 8a ed. . p. 125

32. Nessa linha de raciocínio, prosscguc o doutrinador, ao excmplificar que "uma demonstração disso é a apropriação juridica do primeiro ato de vida - o respirar - operada a partir do conceito de personalidade juridica. Essa ordem de idéias marca o sujeito até para depois de sua morte". (Cf. Luiz Edson Fachin . Teoria Crítica do Direito Civil, pp. 195-196)

33. Cf. Miguel Reale O Projeto do Novo Código Civil : situação após a aprovação pelo Senado Federal . 2a ed. . p. 4 
De fato, ensinam Federico Lara Peinado e Federico Lara González que, entre os diversos textos em escrita cuneiforme achados pelos arqueólogos em suas escavações, um número elevado apresentava importantes informações para a história do Direito escrito, remontando a três mil anos antes de Cristo. ${ }^{34}$

As primeiras leis mesopotâmicas caracterizavam-se pela permanência e pela imutabilidade e, como acreditava-se que as leis em questão tinham origem divina, pouco fazia-se para modificá-las, já que tais modificações trariam a ira dos deuses contra os humanos. ${ }^{35}$

A codificação, nesse período, tinha caráter essencialmente penal e incluiu diversos códigos além do conhecido Código de Hamınurabi, destacando-se o Código de Shulgi (que inspirou o Código de Hammurabi em diversos dispositivos), o Código de Lipit-Ishtar (destacando-se, em comparação com o Código de Shulgi, pelas previsões relativas ao Direito Sucessório e Matrimonial, contendo inclusive referências ao divórcio), o Código de Eshnunna (com um total de sessenta artigos relativos a salários, aluguéis, empréstimo, escravidão, compra e venda, aspectos penais e também o divórcio) e, por fim, a série Ana Ittishu (dispositivos hoje dispersos e que, curiosamente, tratavam também do ensino do Direito nas escolas e sua utilização por juízes, escribas e funcionários, bem como as sanções a que estavam sujeitos os pais ou filhos que questionavam seu parentesco e a sanção à esposa que renegava o seu marido). ${ }^{36}$

$\mathrm{Na}$ verdade, embora possamos apontar diversos exemplos na Antiguidade, o movimento codificador só aparece, de forma significativa, a partir de 1756 com o Codex Bavaricus, na Baviera (ainda admitindo sua complementação pelo Direito Comum, de origem medieval), sendo seguido em 1786 pelo Código Josefino (elaborado durante o reinado de José II, filho de Maria Teresa da Áustria) até culminar, em 1794, naquele que é reconhecido, nas palavras de José Reinaldo de Lima Lopes como "o fruto maduro dessa fase", o Código Civil da Prússia (sob o reinado de Frederico, o Grande). ${ }^{37}$

$\mathrm{Na}$ medida em que o Direito consuetudinário passa a ser substituído pelo Direito legislado, constatamos que o movimento codificador envolveu uma

34. Cf. Federico Lara Pcinado c Federico Lara González . Los Primeros Códligos de La Humanidad .p. IX

35. Cf. Federico Lara Pcinado c Federico Lara Gonzálcz . op. cit. . p. XIII

36. Cf. Federico Lara Pcinado c Federico Lara Gonzálcz . op. cit. pp. XXVI-XXXIII

37. Cf. José Rcinaldo Lima Lopes. O Direito na História : liçõcs introdutórias . p. 208 
mudança de paradigma, relacionada diretamente ao papel desempenhado pelo próprio Estado liberal que substituía o Antigo Regime e foi nesse contexto político que o positivismo desenvolveu-se, esclarecendo José Reinaldo de Lima Lopes que " $a$ legislação desse Estado veio para pôr fim a todo o Direito anterior e seu instrumento privilegiado foi o Código: uma lei que dispunha sistemática e completamente sobre um assunto determinado", 38

Também nessa ordem de idéias, Jacques Ghestin e Gilles Goubeaux apontaram uma tendência natural das revoluções políticas no sentido de buscar a unificação do Direito. ${ }^{39}$

Henri Capitant, com indisfarçável orgulho, destacou que o Código Civil francês tinha servido como modelo para toda a Europa. ${ }^{40}$

Até mesmo na Alemanha, com suas notórias divergências em relação à França, ocorreu a tentativa de codificar o Direito baseada no modelo francês.

Todavia, cumpre ressaltar a existência da célebre polêmica entre Justus Thibaut, professor da Faculdade de Direito da Universidade de Heidelberg e Friedrich Carl Von Savigny, professor da Faculdade de Direito da Universidade de Berlim.

Baseado no relato de Heinrich Lehmann, em 1814, Justus Thibaut, em seu trabalho Über Die Notwendigkeit Eines Allgemeinen Bürgerlichen Rechts Für Deustchland (Da Necessidade de um Direito Civil para toda a Alemanha), defendeu a promulgação de um Código, sendo que essa idéia contou com a oposição ferrenha de Friedrich Savigny, exposta em obra publicada no mesmo ano intitulada Vom Beruf Unsrer eit Für Gesetzgebung Und Rechtswissenschaft e elencando as seguintes objeções: 1) A Prússia e a Áustria não poderiam renunciar aos seus códigos que tinham sido

38. Cf. Josć Rcinaldo Lima Lopcs . op. cit. . p. 223

39. De acordo com Jacques Ghestin c Gilles Goubcaux, "les révolutions ont naturellement tendence à unifier le Droit". Tais autores ainda assevcram que o Código Napolcônico foi visto como o triunfo do individualismo liberal c visou consolidar as conquistas da Revoluçāo Francesa, atcnuando os scus cxcessos c cnccrrando uma fasc de instabilidade política na França, que tinha tambćm uma correspondência no plano legislativo (Cf. Jacqucs Ghestin c Gilles Goubcaux. Traité de Droit civil : Introduction Générale, pp. 83-89)

40. Relatou Henri Capitant que " $c$ "ést ainsi que au commencement du XIX siècle, en France, on a éprouvé l'impérieux besoin de codifier le droit civil, pour mettre un terme à la diversité de notre ancien droit" c "de même l'Italie, puis l'Allemagne, aprés avoir consommé leur unité politique, l'ont complétée par la confection d'un Code Civil". Após cssc brcve rclato histórico, afirmou que "une querelle célèbre s'est engagée sur ce point au commencement du XIXe siécle en Allemagne. L'apparition du Code Civil Français, au début de ce siécle, avait été un événément considérable, et en dehors de sa force d'expansion due aux succès des armes de Napoléon, notre code fut pris pour modèle par toute l'Europe. (Cf. Henri Capitant . Introduction a l'étude du Droit Civil : Notions Générales . 3a cd. pp. 64-65) 
criados recentemente; 2) $\mathrm{O}$ momento político não era adequado para elaborar um bom código e 3) inexistia um léxico jurídico utilizável. ${ }^{41}$

De acordo com Heinrich Lehmann, pelo próprio processo de unificação alemã, prevaleceu o entendimento de Savigny (ainda que temporariamente) e tudo permaneceu como estava até que, a partir da segunda metade do século XIX, fossem desenvolvidos os trabalhos para a elaboração do Código Civil. ${ }^{42}$

Além dos argumentos já expostos, os códigos ameaçavam um mundo já conhecido da nobreza e do clero, setores que representavam a velha ordem e Savigny, ao opor-se ao movimento codificador na Alemanha, invocando a tradição e o espírito do povo alemão na verdade defendia, na visão de José Reinaldo de Lima Lopes, um mundo antigo, "inclusive o modelo antigo de professor, aquele que criava a ordem juridica pelas suas intervenções 'cientificas 'e não se submetia à ordem criada arbitrariamente (não cientificamente) pela legislação". ${ }^{43}$

O espírito do povo alemão, sem qualquer justificativa plausivel, também foi posteriormente invocado a serviço da própria barbárie, corporificada no regime nazista e que contou, lamentavelmente, com o aval de juristas do porte de Carl Schmitt no texto O Führer protege o Direito, no qual afirma que "o Führer leva as advertências da história alemã a sério. Isso lhe dá o direito e a força para fundar um novo Estado e uma nova ordem", pois “o Führer protege o Direito do pior abuso, quando ele no instante do perigo cria o Direito sem mediações", dado que "ele não está sujeito à justiça, ele mesmo foi justiça suprema" ${ }^{44}$

41. Cf. Heinrich Lchmann. Tratado de Derecho Civil : Parte General . v. 1 . tradução de José M. Navas pp. 25-26

42. Aponta Heinrich Lchmann que "venció el criterio de Savigny y todo quedó como estaba. Tan sólo la Asamblea Nacional Alemana de 1849 dió nuevamente expresión a la necesidad de obtener un Derecho Civil uniforme. Sólo se llegó, empero, a la promulgación de la Ordenanza Cambiari y del Código de Comercio, asi como a la elaboración de Proyecto de Derecho de Obligaciones (contra la protesta de Prusia), que se terminó poco antes de la disolución de la federación en 1866 (proyecto de Dresden)"(Cf. Heinrich Lchmann. Tratado de Derecho Civil : Parte General . v. 1 . tradução de Josć M. Navas . p. 26).

43. A questão política foi tambćm a principal razão da dificuldade de implantar a codificação na Alcmanha, vez quc, de acordo com o mesmo autor, tal projeto cra destinado ao fracasso "pois sua viabilidade dependia de não haver um Estado legislador liberal, capaz de impor-se" que cra "aliás, a situação concreta da Alemanha, em que o Código Civil, como queriam seus defensores, viria antecipar a unificação, realizando-a no Direito Privado antes que se realizasse no Direito Público" (Cf. Josć Rcinaldo Lima Lopes . O Direito na História : liçõcs introdutórias . p. 223).

44. Sobre o tcxto $O$ Führer protege o Direito (sobre o Discurso de Adolf Hitler no Reichstag em 13 de julho de 1934), transcrito da página 221 da obra Carl Schmitt e a Fundamentação do Direito, dc Ronaldo Porto Maccdo Jr., cabc frisar que cstc autor ponderou que apesar "do conteúdo ideológico e por vezes panfletário de alguns trabalhos de Schmitt, a sua obra é marcada por uma preocupação cientifica". 
No Direito alemão, ainda que sejam considerados os efeitos do período entre as guerras mundiais, não há como esquecer que, quando dos debates acerca do projeto que culminaria no $B G B$, Anton Menger, visto como um dos precursores do socialismo jurídico na Alemanha e na Áustria, afirmou que o período final do século XIX seria a época mais favorável para uma codificação voltada à proteção das classes economicamente menos favorecidas. ${ }^{45}$

A comparação entre essa afirmação de Anton Menger, no final do século $\mathrm{XIX}$, e os trágicos acontecimentos posteriores ocorridos no período nazista demonstram que é correta a percepção de que a política encontra-se interligada à norma jurídica.

Curiosamente visualizada, nos dias de hoje, como um retrocesso em muitos aspectos, não devemos esquecer que a codificação foi no passado uma inovação absoluta diante de uma acentuada resistência das classes privilegiadas que amparavamse, sobretudo, nos costumes para negá-la.

Dessa forma, não parece correto sustentar que a codificação é em si, isoladamente, um mal ou um bem, refletindo apenas certa visão de mundo que pode ou-não corresponder à visão necessária para solucionar os diversos problemas que nos atingem, como veremos nos pontos seguintes.

5. O processo de descodificação e suas origens.

Parece um fato incontestável que a codificação foi imposta na Europa, seja apenas como decorrência da vontade de um poder central autoritário, ainda que ilustrado (do qual o Código Napoleônico foi o grande exemplo), seja também como um reflexo de um processo de unificação (casos da Itália e da Alemanha).

Contudo, a velocidade dos acontecimentos ocorridos durante o século XX gerou a superação do mundo aparentemente estável e controlável que existiu principalmente na segunda metade do século XIX.

scndo que "a despeito de seu oportunismo politico eticamente questionável e reprovável, a sua própria vida intelectual está marcada por relativa independência intelectual, o que inclusive lhe valeu, algumas ameaças de morte por parte de setores das SS em razão de suas idéias 'incômodas 'para o Reich alemão a partir de 1935".

45. Anton Menger (184l-1906), professor da Faculdade de Dircito da Universidade de Vicna, $\mathrm{cm}$ sua obra $O$ Direito Civil e os Pobres, sustentava que "la mirada del verdadero legislador no se vuelve hacie el pasado, sino que debe contemplar siempre el porvenir", pois "jamás se ha presentado una época más favorable para una atividad creadora de ese género como la actual. Siglos hace que los patronos y los ricos formaban exclusivamente el Derecho Privado, adaptándolo á sua intereses, sin que los pobres, hicieran valer, por miedo o por ignorancia, sus proprios derechos" (Anton Menger. El Derecho Civily los Pobres . tradução de Adolfo Posada . p. 132) 
Tais acontecimentos conduziriam a um processo que seria conhecido como descodificação, entendida aqui como a necessidade de adoção de um processo legislativo mais célere, consubstanciado em leis que não fossem tão extensas, e pronto a responder às múltiplas necessidades de contenção dos litígios, individuais ou transindividuais ${ }^{46}$ que passaram a ocorrer na sociedade.

Sob esse aspecto, Fábio Siebeneichler de Andrade observou que as "mudanças substanciais, tanto de ordem politica quando de natureza econômica, propiciaram o surgimento de uma nova fase: a era da descodificação" e, "de fato os elementos que nortearam o século passado desapareceram" passando da estabilidade própria do século XIX e início do século XX às incertezas permanentes do fim do século XX e do início do século XXI.47

A própria função do Estado passou por uma revisão, dado que um sistema jurídico calcado em Códigos não pode mais enfrentar os problemas sociais que se acumulam e o próprio Direito deixa de atingir seu objetivo maior que é, como já salientamos anteriormente, o de obter a pacificação social.

Não há como negar a inserção, cada vez maior, de termos estranhos ao universo juridico, em que a terminologia empregada em distintas áreas do conhecimento humano passam a integrar a norma.

Sob esse aspecto, aponta Gustavo Tepedino a constatação de "uma alteração radical na linguagem empregada pelo legislador", vez que "as leis passam a ter uma linguagem menos juridica e mais setorial, uma linguagem que, não obstante o protesto dos juristas, atende a exigências especificas, ora atinentes a questões de informática, ora relacionadas a inovações tecnológicas ou a novas operações contratuais, ora a assuntos financeiros ou econômicos, suscitando muitas vezes dificuldades para o intérprete" ${ }^{48}$

Luís Cabral de Moncada, que foi professor catedrático da Universidade de Coimbra, já alertava para o fato de que "essa obra de barragem que foram os códigos, acha-se, com efeito, comprometida nos diferentes campos do Direito", pois "a torrente avassaladora das leis dispersas ameaça romper, de novo, todos diques

46. Os interesses transindividuais destacaram-se a partir da segunda metade do século $\mathrm{XX}$, na qual tais interesses (scjam cles difusos, colctivos ou individuais homogêncos) foram identificados c passaram a chamar a atcnção do legislador. No Brasil, destacam-sc a Lci n. 6.938/8I (Politica Nacional do Mcio Ambicntc), a Lci n. 7.347/85 (Ação Civil Pública) c a Lci n. 8.078/90 (Código de Defcsa do Consumidor).

47. Cf. Fábio Sicbencichler de Andrade . op. cit. pp. 171

48. Cf. Gustavo Tepedino. Temas de Direilo Civil . 2a cd. . p. 9 
com aquela pletora ofensiva de leis", e não era dificil, para o doutrinador lusitano, encontrar as explicações para tal fato, que estariam na idolatria da lei e nas transições e transformações próprias da vida contemporânea, na qual o Estado tem a necessidade de assumir funções que sempre foram estranhas à sua tradicional atividade. ${ }^{49}$

Assim, a atuação da Jurisprudência seria fundamental para amoldar as concepções antiquadas de um Código à realidade, atuação esta sempre somada à vigência de novas leis especiais, tal como sustentou Henri Capitant ao tratar do tema. ${ }^{50}$

Fábio Siebeneichler de Andrade, em que pese o fato de sustentar a utilidade da codificação, relata expressivos argumentos a favor da descodificação, no sentido de que "a idéia de código estruturado como um sistema fechado, geschlossen system, não se mostraria apta a enfrentar os problemas vivenciados pela sociedade atual; depois os principios constitucionais teriam substituido os conceitos do Código Civil; mais ainda, as principais categorias do código também não seriam capazes de atender às necessidades sócio-econômicas atuais" e, "em conseqüência, acentua-se o desenvolvimento das leis especiais, que passam a constituir-se por força de seu grande número e importância, em verdadeiros microssistemas" que retirariam do Código Civil o relevante papel que o mesmo desempenhava até então no sistema jurídico. ${ }^{51}$

O mesmo Fábio Siebeneichler de Andrade posiciona-se contrariamente a tais afirmações, dizendo que elas só demonstram uma consistência aparente, relatando que a tendência a codificar não teria desaparecido, com novos países codificando o seu Direito Privado e negando-se a "compartilhar a tese de que teriam somente uma função microeconômica, enquanto às leis especiais caberia uma incumbência de caráter macroeconômico", pois as leis especiais não se caracterizam como um sistema já que visam resolver apenas problemas específicos e com vigência limitada. ${ }^{52}$

49. Cf. Luís Cabral de Moncada . Lições de Direito Civil. 4a cd. . p. 127-128

50. Para Henri Capitant "il faut en conclure que la codification ne doit pas être trop souvent répétée. Il est préférable de vivre sur un Code vieux, tout en le modifiant par des lois spéciales, plus faciles $\dot{a}$ élaborer, quant à ses parties qui ne correspondent plus aux conceptions actuelles, et de laisser à la jurisprudence, éclairée et dirigée par la doctrine, le soin de travailler sur ce fonds de textes, de les remanier, de les transformer insensiblement". E conclui dizcndo que " $c$ "est à elle qui il faut, en première religne, confier la tâche de réparer les fissures qui se produisent dans l'edifice, au besoin mềne d'y changer quelques pierres, d'en modifier quelques parties. C'est par elle, toujours en contact avec la vie. que se fera désormais e progrés du droit, son adaptation au milieu social, et ainsi, avec une base solide et résistante faite de droit ècrit, on laisser au droit toute sa souplesse, toute son aptitude à se modifier, en même temps que les faits eux-mêmes, pour être toujours d'accord avec eux " (Cf. Henri Capitant Introduction a l'étude du Droit Civil : Notions Générales . 3a cd. . p. 71).

51. Cf. Fábio Sicbencichler de Andrade . op. cit. pp. 171-172

52. Cf. Fábio Sicbencichler de Andrade . op. cit. . p. 172 
Ainda que com certa limitação de incidência, as leis especiais desempenhariam um importante papel, constituindo para Orlando Gomes verdadeiros "microssistemas", pois as chamadas leis especiais ou extravagantes nada teriam de especiais, "eis que não são desdobramento de institutos codificados, não regulam matéria estranha ao conteúdo do Direito Privado, nem apanham menor número de destinatários ou de hipóteses", constituindo "distintos 'universos legislativos' de menor porte, denominados por um autor, com muita propriedade, 'microssistemas tal como sucede, por exemplo, com o regime das locações. ${ }^{53}$ Estes microssistemas são refratários à unidade sistemática dos códigos porque têm a sua própria filosofia e enraizam em solo irrigado com águas tratadas por outros critérios, influxos e métodos distintos" ${ }^{54}$

Não há como, de acordo com Gustavo Tepedino, fugir de tal realidade, tal conclusão surge da constatação de que a alteração "no papel do Código Civil representa uma profunda alteração na própria dogmática" identificando-se "sinais de esgotamento das categorias do Direito Privado", pois "os novos fatos sociais dão ensejo a soluções objetivistas e não mais subjetivistas, a exigirem do legislador, do intérprete e da doutrina uma preocupação com o conteúdo e com as finalidades das atividades desenvolvidas pelo sujeito de direito" $5 s$

Concluindo, ainda que recorramos ao positivismo, enquanto corrente jus-filosófica melhor vocacionada a amparar a codificação, é fundamental estabelecer que, mesmo tal corrente, não mais admite um dogmatismo exacerbado, tendo reformulado suas concepções originais e adotando hodiernamente postura mais flexível, sendo tal a distância do ponto de origem que há a indagação a respeito de ser correto ainda designá-la por tal denominação. ${ }^{56}$

53. Acrescenta Gustavo Tepedino à lição do saudoso civilista que "a Constituição de 1988 retrata uma opção legislativa concordatária, em favor de un Estado social destinado a incidir, no que concerne às relações juridicas privadas, sobre um Direito Civil repleto de leis especiais, chamadas de estatutos, que disciplinam exaustivamente inteiras matérias extraidas da incidência do Código Civil. O Estatuto da Criança e do Adolescente, o Código de Defesa do Consumidor, a Lei de Locaçōes, já reproduzindo outras leis anteriores à Constituição, como o Estatuto da Terra, todos esses universos legislativos apresentamse radicalmente diversos das legislações excepcional e especial de outrorar", pois "não se tem aqui, do ponto de vista técnico, uma relação de gênero e espécie, ou de Direito comum e especial, senão a subtração verdadeira e própria de institutos - ou porque não alvitrados pelo Código Civil ou porque revogados por leis especiais, o que sucedeu em relação a um número cada vez maior de matérias". (Cf. Gustavo Tcpedino. Temas de Direito Civil . 2a cd. . p. 8)

54. Cf. Orlando Gomes . Introdução ao Direito Civil 14a cd. . p. 69

55. Cf. Gustavo Tepedino . Temas de Direito Civil . 2a cd. . p. 6

56 . De acordo com Norbcrto Bobbio, "quanto al positivismo come teoria del diritto, credo sia bene distinguere un significato stretto e un significato ampio della teoria. Se si dovesse intendere per positivismo 
6. A Codificação no Mundo Contemporâneo: as mudanças de paradigma e o paradigma pós-moderno.

A técnica jurídica não basta por si só, pois o intérprete não pode mais dispensar o recurso a conceitos oriundos da economia, da biologia e de outras ciências que contribuem, cada vez mais, para tornar a decisão judicial cada vez mais difícil de ser prolatada. ${ }^{57}$

Esse fator é desencadeado pela própria complexidade dos problemas existentes em uma sociedade marcada por sua heterogeneidade. Não temos apenas um grupo social uniforme a reivindicar a tutela do Estado para a solução dos conflitos cotidianos.

A lição de Antonio Junqueira de Azevedo, em seu artigo O Direito PósModerno e a Codificação é no sentido de que "no campo do direito, a consideração da 'realidade como é' parece ao jurista pressuposto básico para a muito procurada segurança jurídica : a simples dúvida sobre a aptidão de o pensamento refletir a realidade incomoda. Paralelamente, outra caracteristica dos tempos pós-modernos, a hiper-complexidade, que, no mundo juridico, se revela na multiplicidade de fontes do direito, quer materiais - porque, hoje, são vários os grupos sociais, justapostos uns aos outros, todos dentro da mesma sociedade mas sem valores compartilhados (shared values), e cada um, querendo uma norma ou lei especial para si -, quer formais-com um sem número de leis, decretos, resoluções, códigos deontológicos, avisos, etc. etc.quebram a permanente tendência à unidade do mundo do direito" 58

Ricardo Lorenzetti constata a proliferação legislativa, acompanhada pelo crescente desconhecimento das leis por parte da população e, dessa forma, “o código

giuridico unicamente il 'codicismo', la teoria dell 'interpretazione meccanica della legge, credo avrebbero ragione colore che propongono discartalo per l'ottima ragione che è smentito dai fatti ma dall'epoca del cosiddetto feticismo legislativo molta acqua è passata sotto $i$ ponti, e nessuno crede più seriamente al giudece come automa", porquc "si trata di vedere se convenga chiamare positivismo giuridico la teoria allargata, che ha mutato o va mutando radicalmente le idee sull'interpretazione giuridica e sull'opera della scienza del diritto" (Cf. Norbcrto Bobbio. Giusnaturalismo e Positivismo Giuridico . 3a cd. . p. 125)

57. Apesar disso, ć importante resgatar as palavras de Arnoldo Wald, advertindo que “o progresso juridico deve acompanhar o crescente controle realizado pelo homem sobre os bens exteriores, aperfeiçoando paralelamente as relações interindividuais e dando às conquistas cientificas um colorido e uma finalidade de ordem moral, pois é o aspecto moral que distingue a civilização da simples técnica"(Cf. Arnoldo Wald . "O Dircito da Crisc". O Direito na Década de 80 : Estudos Juridicos em Homenagem a Hely Lopes Meirelles . p. 290)

58. Cf. Antonio Junqucira de Azcvedo. O Dircito Pós-Moderno c a Codificação . Revista de Direito do Consumidor n. 33 .p. 123 
perde abrangência, a legislação especial é derrogatória dos princípios gerais codificados", sendo "dificil estabelecer uma ordem e, mais ainda, manter principios axiomáticos" 59

Logo, segundo o autor, a tarefa de interpretar a norma fornou-se fundamental, tanto na Doutrina como na Jurisprudência e "a linguagem juridica contaminou-se de genética, economia, moral, tecnologia, computação" e, em razão disso estariamos diante de "não-somente uma descodificação legislativa, mas também um problema de explosão, com uma enorme força centripeta, desintegradora, no plano da lei, de outras fontes, da Doutrina e do Direito Privado em geral" 60

Como apontou Ricardo Lorenzetti, durante certo periodo, "o código constituiu-se em um reflexo da criação do Estado nacional; sua pretensão era ordenar as condutas jurídico-privadas dos cidadãos de forma igualitária; uma só norma, aplicável por igual, a todos os cidadãos, sejam nacionais ou estrangeiros", tornandose o código "uma garantia de separação entre a sociedade civil e o Estado" ${ }^{1}$

Assim, atualmente, o Direito Civil "não se funda em uma só lei codificada; ao contrário, há muitas leis para distintos setores de atividade e de cidadãos", pois "a idéia de ordenar a sociedade ficou sem efeito a partir da perda de prestigio das visões totalizadoras; o Direito Civil se apresenta antes como estrutura defensiva do cidadão e de coletividades do que como 'ordem social" e o Código Civil perde sua centralidade diante dos microssistemas jurídicos. ${ }^{62}$

Dessa forma, relata Gustavo Tepedino que "a tônica excessiva do Código Civil em torno do sujeito de direito cede à atenção do legislador especial para com as atividades, seus riscos e impacto social, e para a forma de utilização dos bens disponiveis, de maneira a assegurar resultados sociais pretendidos pelo Estado", considerando que "a legislação especial é o instrumento dessa profunda alteração, avalizada pela Constituição da República" ${ }^{3}$

O que há, realmente, é uma mudança de paradigma, vez que o recurso a uma única lei, elaborada dentro de uma visão totalizadora dos problemas sociais, não

59. Cf. Ricardo Lorenzctti Fundamentos do Direito Privado tradução de Vera Maria Jacob de Fradera p. 44

60. Cf. Ricardo Lorenzetti . op. cit. . p. 44

61. Cf. Ricardo Lorenzetti Fundamentos do Direito Privado tradução de Vera Maria Jacob de Fradcra, pp. 44-45

62. Cf. Ricardo Lorenzetti Fundamentos do Direito Privado tradução de Vera Maria Jacob de Fradcra.p. 45

63. Cf. Gustavo Tepedino. Temas de Direito Civil . 2a cd. . p. 7 
mais pode ser considerada como satisfatória para a resolução de conflitos que avançam em progressão geométrica. ${ }^{64}$

7. O Novo Código Civil brasileiro (Lei n. 10.406/02) e suas perspectivas, enquanto ordenador do Sistema Jurídico do Direito Privado

Após analisarmos até aqui as diversas correntes que sustentaram a necessidade da codificação ou ainda a sua superação, ainda não foi totalmente respondida a questão formulada inicialmente, sobre qual seria a função do novo Código Civil em nosso ordenamento jurídico.

Fábio Siebeneichler de Andrade aponta a nova missão de um Código Civil na atualidade, ressaltando que "não será, é claro, a mesma idéia anterior, em que a concepção totalizante aparecia num grau muito intenso" pois "assegurada a atualidade do Código como forma de legislação, cabe, inicialmente, resgatar a figura do Código Civil como ordenador do sistema jurídico do Direito Privado" ${ }^{65}$

Para a consecução de tal objetivo, Fábio Siebeneichler de Andrade defende a utilização das cláusulas gerais, bem como uma revitalização da Doutrina, concluindo que "a codificação, hoje colocada numa situação de crise, dificilmente poderá ser substituida ou superada" visto que a codificação simboliza " uma categoria altamente representativa que por estar associada ao principio da continuidade sempre estará a (co)ordenar o Direito Privado" 66

Podemos também defender a codificação como instrumento principiológico, tal como ocorre na Lei n. 8.078/90 (Código de Defesa do Consumidor), tal como ensina Nélson Nery Júnior, para quem tal lei teria essa característica, porque "não é analítica, mas sintética", já que "nem seria de boa técnica legislativa aprovarse lei de relações de consumo que regulamentasse cada divisão do setor produtivo",

64. Nesse scntido, a inovadora lição de Antonio Junqueira de Azcvedo (fundada na tcoria dos paradigmas dc Thomas Kuhn), para quem o paradigma da lei limitou o legislador de 1916, cmbora mesmo o legislador de 2002 ainda estaria preso ao paradigma do juiz, por mcio dos conccitos indetcrminados ou abcrtos (que podem scr encontrados com freqüência no novo Código). Essa visão do lcgislador cstaria determinada por uma fasc tida como moderna, scndo que esta já foi supcrada pcla fasc pós-moderna, na qual há uma hiper-complexidade que torna o simples recurso à libcrdade do juiz para precnchimento da norma no caso concreto, uma medida insuficiente para resolver os problemas contemporâncos (Cf. Antonio Junqueira de Azcvedo . O Dircito Pós-Moderno c a Codificação . Revista de Direito do Consumidor n. 33, pp. 125-126).

65. Cf. Fábio Sicbencichler de Andrade .op. cit. p. 172

66. Cf. Fábio Sicbencichler de Andrade . op. cit. . p. 173 
mas sim "aprovar lei que contivesse preceitos gerais, que fixasse os principios fundamentais das relações de consumo. É isto que significa ser uma lei principiológica". 67

Esse raciocínio poderia ser aplicado ao Código Civil, sempre visto como lei de caráter geral?

Embora não neguemos todas as críticas esboçadas até aqui, entendemos que sim (destacando que, para nós, essa seria hoje a sua principal e talvez até sua única função), até porque diversos princípios estão contidos nesse diploma, o que condicionaria as leis especiais em que há, primordialmente, apenas relações de caráter civil, com igualdade entre as partes (o que excluiria as relações de trabalho e também as relações de consumo, a não ser que as normas civis, aplicáveis subsidiariamente, favoreçam a parte mais fraca).

Gustavo Tepedino critica a visão dos que são favoráveis à codificação, substituindo estas por uma visão constitucional do Direito Civil, pois as constituições assumem compromissos " a serem levados a cabo pelo legislador ordinário, demarcando os limites da autonomia privada, da propriedade e do controle de bens", e "o Código Civil perde, assim, definitivamente, o seu papel de Constituição do Direito Privado", pois "os textos constitucionais, paulatinamente, definem principios relacionados a temas antes reservados exclusivamente ao Código Civil e ao império da vontade" e "o próprio Direito Civil, através da legislação extracodificada, desloca sua preocupação central, que já não se volta tanto para o individuo, senão para as atividades por ele desenvolvidas e os riscos dela decorrentes" 68

O jurista do Rio de Janeiro complementa seu raciocínio, ao criticar o individualismo próprio do auge da codificação e afirmar que o papel constitucional do Direito Civil "e a crença do individualismo como verdadeira religião marcam as codificações do século XIX e, portanto, o nosso Código Civil”, pois, nessa época o Direito Público não interferia na esfera privada, "assumindo o Código Civil, portanto, o papel único e monopolizador das relações privadas", já que o Código "almejava a completude, que justamente o deveria distinguir, no sentido de ser destinado a regular, através de situações-tipo, todos os possiveis centros de interesse juridico de que o sujeito privado viesse a ser titular". ${ }^{69}$

67. Cf. Nćlson Nery Júnior. Códligo Brasileiro de Defesa do Consumidor : comentado pelos autores do anteprojeto . 6a cd. coordenação de Ada Pellegrini Grinover . p. 432

68. Cf. Gustavo Tepedino . Temas de Direito Civil . 2a cd. . p. 7

69. Cf. Gustavo Tcpedino . op. cit. . p. 3 
No auge da codificação, na França, afirma Louis Assier-Andrieu que a lei era um verdadeiro objeto de culto e, assim, "substituiu-se a reverência devida ao monarca pela adoração de uma abstração derivada, pelos filósofos da razão universal, sem mudar a estrutura ritual de fidelidade e submissão" 70

Não há como, no mundo atual, pretender a segurança (e ao mesmo tempo, a submissão, como bem sublinhou Louis Assier-Andrieu) absoluta de outrora em uma sociedade pautada pela heterogeneidade.

Contextualizando historicamente o Código Civil brasileiro, aprovado em 1916, Gustavo Tepedino, salienta que este foi, antes de mais nada, "fruto de uma época que Stefan Zweig, em sintese feliz, designaria como 'o mundo da segurança' Segurança - é de se sublinhar - não no sentido dos resultados que a atividade privada alcançaria, senão quanto à disciplina balizadora dos negócios, quanto às regras do jogo", posto que "ao Direito Civil cumpriria garantir à atividade privada" e em particular ao sujeito de direito, a estabilidade proporcionade por regras quase imutáveis nas suas relações econômicas" 72

Para Luiz Edson Fachin, "parece fundamental, todavia, abandonar-se a postura da segurança dos conceitos, uma vez que, em certa medida, as explicações segmentadas conduzem a uma banalização da complexidade dos problemas" e conclui, com amargo, mas incontestável realismo que "hoje, mais do que nunca, deve o estudioso afeiçoar-se a perguntas sem resposta"73

Em conclusão, podemos tomar emprestadas as palavras de Luiz Edson Fachin, já que o número de indagações que podemos continuar a elaborar é infinitamente maior do que as respostas que poderemos obter, tanto do legislador, como dos julgadores ou, ainda, da própria Doutrina.

Apesar de tudo que relatamos, não há como negar que a proliferação legislativa, embora num grau consideravelmente menor, também ocorreu no passado,

70. Cf. Louis Assicr-Andricu . O Direito nas Sociedades Humanas tradução de Maria Ermantina Galvão . p. 249

71. A csse respcito, em 1994, Carlos Alberto Bittar insistia que, "no contexto atual, mesclam-se no âmbito privado, as regras gerais codificadas, de inspiração liberal, em que as pessoas são tomadas em nivel de relação paritária, com outras resultantes da intervenção estatal, dentro das concepçós. socializantes que se expandiram em nosso século, nos quais se intenta tomar as pessoas não como individuos, mas como seres integrados à vida social, econômica e politica do pais". (Cf. Carlos Alberto Bittar Curso de Direito Civil.v. 1. p. 18)

72. Cf. Gustavo Tepedino. Temas de Direito Civil. 2a cd. p. 3

73. Cf. Luiz Edson Fachin . Teoria Crítica do Direito Civil. p. 195 
pois como ensina Renan Lotufo: "ocorre que a produção legislativa é sempre crescente nas sociedades, e a multiplicidade de leis, afora os conflitos possiveis, implicando em se saber quais as normas vigentes para aplicação ao caso concreto, no tempo e espaço, começou a requerer os trabalhos de compilação. Estas começaram a ser unitárias $e$ orgânicas, com uma estrutura lógica", o que culminou na codificação. ${ }^{74}$

Estaríamos, então, andando em círculos? Ou sucumbiríamos à constatação de que numa sociedade em transformação cada vez mais acelerada, na qual a uniformidade de outrora é substituída pela diversidade cultural e axiológica, só nos resta admitir que a perplexidade do jurista é apenas mais um dos sintomas da pósmodernidade?

Diante dessas considerações, temos de reconhecer que as respostas ainda estão por vir, mas que o debate pode e sobretudo deve permanecer, mesmo com a edição do novo Código Civil...

\section{Conclusões.}

1) A codificação surgiu como um movimento decorrente das injunções políticas dos séculos XVIII e XIX, ora por influência direta dos Estados liberais e ora por reação dos Estados absolutistas que eram governados por soberanos identificados com o que se convencionou denominar de despotismo esclarecido (como foi o caso do Código da Prússia, aprovado em 1794, no reinado de Frederico, o grande).

2) Comparando a codificação com a Consolidação, observamos que a primeira apresenta como característica fundamental a preocupação com a sistematização normativa, ausente na última.

3) Nessa ordem de raciocínio, o juspositivismo pode ser considerado como a corrente jusfilosófica mais adequada à codificação, já que esta tinha como escopo eliminar (principalmente negando) as lacunas do ordenamento jurídico. Apesar disso, sequer é correto visualizar no positivismo contemporâneo, na lição de Norberto Bobbio, a mesma corrente que ensejou o que costumou designar-se por fetichismo da lei.

4) É fato que, mesmo diante da aprovação da Lei n. 10.406/02, a codificação hoje não terá mais condições de desempenhar o mesmo papel totalizante e sistemático que desempenhava no passado, sem que fosse necessário recorrer ao 
legislador para que este venha a suprir as cada vez mais constantes lacunas do ordenamento jurídico. Todavia, não se quer desprezar a relevância principiológica dos códigos, única justificativa para a manutenção dos mesmos no mundo contemporâneo.

5) Complementando a conclusão anterior, sustentamos que o novo Código Civil brasileiro (Lei n. 10.406/02) poderá revelar utilidade, na medida em que dele se espere apenas um vetor principiológico (o que, em certa medida, já era atingido por meio da Constituição Federal, embora ocorra aí, um certo desvio de sua função original) e não um repositório de soluções para os problemas da vida contemporânea, que apresentam uma hiper-complexidade cada vez mais acentuada.

São Paulo, julho de 2003. 
Bibliografia

ANDRADE, Fábio Siebeneichler de . Da Codificação : Crônica de um Conceito . Porto Alegre : Livraria do Advogado, 1997.

ASSIER-ANDRIEU, Louis . O Direito nas Sociedades Humanas tradução de Maria Ermantina Galvão São Paulo : Martins Fontes, 2000.

AZEVEDO, Antonio Junqueira de. O Direito Pós-Moderno e a Codificação. Revista de Direito do Consumidor, São Paulo : Revista dos Tribunais, n. 33, pp. 123129 , jan./mar. 2000.

BITTAR, Carlos Alberto. Curso de Direito Civil. v. 1 . Rio de Janeiro : Forense Universitária, 1994.

BOBBIO, Norberto Giusnaturalismo e Positivismo Giuridico . $3^{\mathrm{a}}$ ed. . Milão : Edizioni di Comunità, 1977.

BRUSIIN, Otto O Pensamento Jurídico tradução de Hebe A. M. Caletti Marenco Campinas : Edicamp, 2001.

CAPITANT, Henri . Introduction a l'étude du Droit Civil : Notions Générales $3^{\text {a }}$ ed. . Paris : A. Pedone, 1912.

ESTRADA, Liniers de Manual de Historia del Derecho Buenos Aires : Abeledo-Perrot, 1993.

FACHIN, Luiz Edson . Teoria Crítica do Direito Civil . Rio de Janeiro : Renovar, 2000.

FERRAZ JÚNIOR, Tércio Sampaio . Introdução ao Estudo do Direito : técnica, decisão, dominação $2^{\mathrm{a}}$ ed. São Paulo : Atlas, 1994.

FREITAS, Augusto Teixeira de Consolidação das Leis Civis $2^{\mathrm{a}}$ ed. Rio de Janeiro : Typographia Universal de Laemmert, 1865.

GHESTIN, Jacques e GOUBEAUX, Gilles . Traité de Droit civil : Introduction Générale . Paris : L.G.D.J., 1977.

GOMES, Orlando Introdução ao Direito Civil $14^{\mathrm{a}}$ ed. atualizada por Humberto Theodoro Júnior . Rio de Janeiro : Forense, 1999.

GONZÁLEZ, Federico Lara e PEINADO, Federico Lara . Los Primeros Códigos de la Humanidad Madri : Tecnos, 1994.

LOPES, José Reinaldo de Lima O Direito na História : Lições Introdutórias São Paulo : Max Limonad, 2000.

LOPES, Miguel Maria de Serpa . Curso de Direito Civil v. $18^{\mathrm{a}}$ ed . revista e atualizada por José Serpa Santa Maria Rio de Janeiro : Freitas Bastos, 1996.

LORENZETTI, Ricardo Luis . Fundamentos do Direito Privado tradução de Vera Maria Jacob de Fradera São Paulo : Revista dos Tribunais, 1998.

LOTUFO, Renan Curso Avançado de Direito Civil Parte Geral v. 1 São Paulo : Revista dos Tribunais, 2002.

MACEDO JÚNIOR, Ronaldo Porto Carl Schmitt e a Fundamentação do Direito São Paulo: Max Limonad, 2001.

MENGER, Anton. El Derecho Civil y los Pobres tradução de Adolfo Posada Granada : Comares, 1998. 
MONCADA, Luís Cabral de Lições de Direito Civil. 4a ed. Coimbra : Almedina, 1995.

MONTORO, André Franco . Introdução à Ciência do Direito . v. II . 7ª ed.. São Paulo : Revista dos Tribunais, 1979.

MIRANDA, Pontes de . Fontes e Evolução do Direito Civil Brasileiro . $2^{\mathrm{a}} \mathrm{ed}$. Rio de Janeiro : Forense, 1981.

NERY JÚNIOR, Nélson. Código Brasileiro de Defesa do Consumidor : comentado pelos autores do anteprojeto . $6^{\mathrm{a}}$ ed. Ada Pellegrini Grinover (coord.) . Rio de Janeiro : Forense Universitária, 1999.

PINTO, Carlos Alberto da Mota . Teoria Geral do Direito Civil . $3^{\mathrm{a}}$ ed. Coimbra : Coimbra Editora, 1996.

PORTALIS, Jean Etienne Marie .Discurso Preliminar al Código Civil Francés tradução de I. Cremades e L. Gutiérrez-Masson . Madri : Civitas, 1997.

REALE, Miguel . O Projeto do Novo Código Civil : situação após a aprovação pelo Senado Federal $2^{a}$ ed. São Paulo : Saraiva, 1999.

TEPEDINO, Gustavo . Temas de Direito Civil . $2^{a}$ ed. . Rio de Janeiro : Renovar, 2001.

WALD, Arnoldo "O Direito da Crise" O Direito na Década de 80 : Estudos Jurídicos em Homenagem a Hely Lopes Meirelles coordenação de Arnoldo Wald São Paulo : Revista dos Tribunais, 1985, pp. 282-298 